\title{
Quantifying environmental heterogeneity: habitat size necessary for successful development of cod Gadus morhua eggs in the Baltic Sea
}

\author{
B. R. MacKenzie ${ }^{1, *}$, H.-H. Hinrichsen ${ }^{2}$, M. Plikshs ${ }^{3}$, K. Wieland ${ }^{4}$, A. S. Zezera ${ }^{5}$ \\ ${ }^{1}$ Danish Institute for Fisheries Research, Kavalergården 6, 2920 Charlottenlund, Denmark \\ ${ }^{2}$ Institut für Meereskunde Kiel, Düsternbrooker Weg 20, $24106 \mathrm{Kiel}$, Germany \\ ${ }^{3}$ Latvian Fisheries Research Institute, 6 Daugavgrivas str., 1007 Riga, Latvia \\ ${ }^{4}$ Danish Institute for Fisheries Research, North Sea Centre, PO Box 101, 9850 Hirtshals, Denmark \\ ${ }^{5}$ Atlantic Scientific Research Institute of Marine Fisheries and Oceanography (AtlantNIRO), 5 Dm. Donskoy St., \\ Kaliningrad 236000, Russia
}

\begin{abstract}
Spatial and temporal variability in environmental factors can exert major influences on survival and growth of living organisms. However, in many key areas of fisheries science (e.g. growth, survival and recruitment determination), environmental heterogeneity is usually ignored because of insufficient environmental or fisheries data or lack of evidence that such heterogeneity impacts response variables. For the eastern Baltic Sea (ICES Subdivisions 25 to 32), we evaluated spatial and temporal differences in conditions affecting the survival of cod Gadus morhua L. eggs at survival on four distinct spawning sites within the assessment area. We intercalibrated ways of quantifying the volume of water ('reproductive volume') at each site where salinity, oxygen and temperature conditions permitted successful egg development. We have developed and compared a time series (1952 to 1996) of reproductive volumes among the areas to identify spatial differences. The results of 2 independent volume-estimation methods are comparable, indicating that highly significant differences exist among the sites, and that the westernmost spawning ground, Bornholm Basin, has on average the highest reproductive volume and the lowest variability among the 4 sites. These findings may be useful in evaluating how spatial and temporal variability in environmental conditions affect egg hatching success and possibly recruitment in the Baltic stock.
\end{abstract}

KEY WORDS: Baltic Sea · Cod eggs · Environmental heterogeneity - Oxygen - Survival · Spatial distributions

\section{INTRODUCTION}

The cod Gadus morhua L. population in the eastern Baltic Sea is confronted with a set of environmental conditions which differ from those experienced by populations in all other geographic areas. Here cod eggs are neutrally buoyant in relatively deep water (>50 m deep; salinity 10 to 15 psu) due to the low salinity of the surface layer ( 6 to $8 \mathrm{psu}$ ). In contrast, cod eggs in other areas, where surface salinities are typically $>28$ psu, are neutrally buoyant in the upper 20 to $50 \mathrm{~m}$

\footnotetext{
•E-mail: brm@dfu.min.dk
}

(e.g. Kjesbu et al. 1997). As a result cod eggs in the Baltic have a vertical distribution which is concentrated in deep water and usually near or below the permanent halocline (Grauman 1984, Wieland \& JarreTeichmann 1997, Wlodarczyk \& Horbowa 1997).

This vertical distribution frequently results in cod eggs being exposed to water with a very low oxygen concentration (e.g. Nissling et al. 1994, Wieland et al. 1994). Water masses in the deep parts of the Baltic basins are situated below a permanent halocline that greatly inhibits the role of vertical mixing in renewing oxygen levels in the deep layers (Stigebrandt 1987). As a result, oxygen levels below the halocline can become extremely low due to aerobic metabolism and the 
decomposition of organic matter sinking from the surface layer (Stigebrandt \& Wulff 1987).

The main process which can reverse this situation is the occasional inflow of oxygen-rich waters from the North Sea (Matthäus \& Franck 1992). In the absence of such inflows, oxygen concentrations below the halocline progressively decrease to $<2 \mathrm{ml}^{-1}$, concentrations at which no Baltic cod eggs will develop and hatch successfully (Wieland et al. 1994). As a result the thickness of the layer of water ('spawning layer': Plikshs et al. 1993) with suitable salinity and oxygen conditions decreases until no water remains in which successful egg development can take place. In the Baltic, areas most remote from the influence of North Sea inflows tend to be most susceptible to anoxic conditions in the deep layers (HELCOM 1996). Hence there are often strong spatial gradients (horizontally and vertically) in oxygen conditions within the Baltic Proper.

It has been widely believed among Baltic fisheries scientists and oceanographers for many years that such interactions are critical for successful reproduction and a prerequisite for strong year-classes (e.g. Grauman 1973, Kosior \& Netzel 1989, Bagge et al. 1994, Helcom 1996, Schnack et al. 1996, ICES 1998). However, in order to evaluate this hypothesis statistically, it would be helpful if the volume of water suitable for cod egg development could be quantified. This volume of water (called the 'reproductive volume' by Plikshs et al. 1993) would effectively represent a measure of habitat size for this particular life-history stage.

In an initial attempt to quantify habitat size for cod eggs in the Baltic, Plikshs et al. (1993) estimated reproductive volumes at each of the 4 main spawning sites (see Fig. 1), i.e. the Bormholm Basin, the Gdansk Deep, and the southern and the central Gotland Basin, in different months for the years 1952 to 1992. Volumes were estimated by horizontally integrating the spawninglayer thickness estimated at a single central hydrographic station across the area of each basin. Their time series indicate that volumes varied greatly between the 4 basins and between years. In addition, they found statistical evidence that recruitment was positively related to total reproductive volume (after allowing for spawning stock biomass), and 2 subsequent studies using the same reproductive volume data but a different recruitment time series obtained a similar result (Sparholt 1996, Jarre-Teichman et al. in press).

In the future, such studies may not be possible because hydrographic sampling efforts changed during the 1990s. The Latvian time series in the Bornholm and Gdansk Basins stopped in 1992, but has continued in the Gotland Basin (Plikshs pers. comm.). A new historical time series for the Bornholm Basin has been constructed by the University of Kiel (Hinrichsen \& Wieland 1996) and is being continued (Hinrichsen

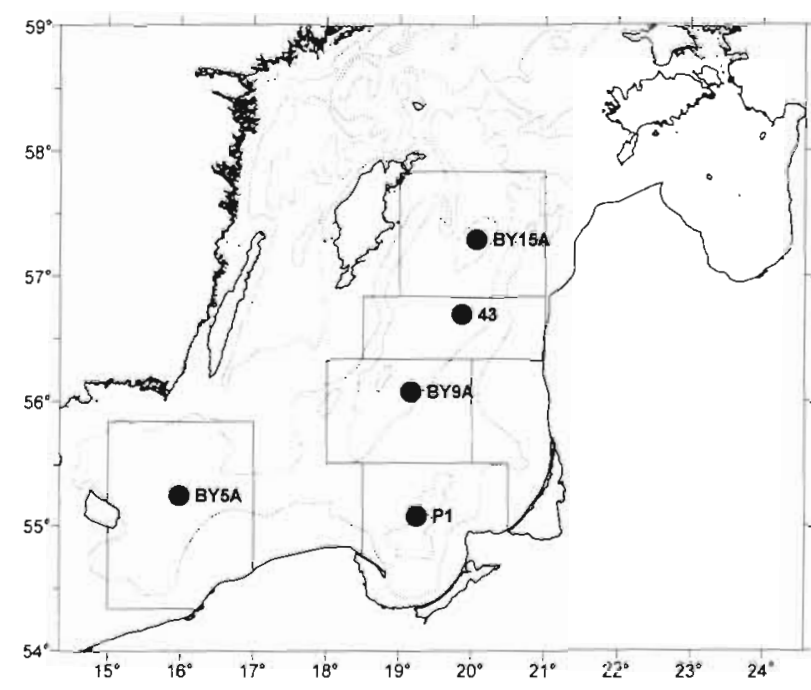

Fig. 1. Map of Baltic Sea showing locations of hydrographic sampling sites ( ) and boxes within which reproductive volumes were calculated by Plikshs et al. (1993). Stns BY5A, P1, BY9A, 43, and BY15A are located in Bornholm Basin, Gdansk Basin, southern Gotland Basin and central Gotland Basin (Stns 43 and BY 15A), respectively

pers. comm.); however the Kiel measurements are being compiled by different methods (e.g. more stations per basin) and hydrographic data than the Latvian estimates. Moreover, the Kiel measurements do not provide information about conditions in the Gdansk and Gotland Basins. Russian investigators have been developing estimates of reproductive volume in the Gdansk and southern Gotland Basins (Feldman et al. 1996, Zezera \& Zezera 1997) using a methodology similar to that of Plikshs et al. (1993), but using multiple hydrographic stations per basin. The changes in sampling effort and methods mean that it may no longer be possible to obtain a complete and unbiased representation of conditions in all areas for all years.

In this paper, we compare and intercalibrate the methodologies for volume estimation so that new series can be developed and used in future modelling studies (e.g recruitment, eutrophication). First, we present a full description of these methodologies, characterise some of the main statistical features of the reproductive volume distributions, and evaluate the degrec of spatial variability between spawning areas. Second, we evaluate the hypothesis that 1 hydrographic station is sufficient to represent a whole basin for the purpose of estimating its reproductive voiume. This hypothesis was evaluated because all of the reproductive volume data used in previous recruitment-modelling exercises (Plikshs et al. 1993, Sparholt 1996) were based on 1 hydrographic station per spawning area, even though various types of mesoscale horizontal and vertical motions (e.g. inflows 
from Arkona basin and areas to the west, coastal upwelling, internal waves) could affect hydrographic conditions in some areas of a given basin but not elsewhere within the same basin (Zezera \& Zezera 1997).

\section{METHODS}

Reproductive volumes were estimated in different ways and with different data sources by 2 institutes. The sequence of data collection, processing, calibration and comparison is described in detail in the following subsections.

Estimation methodology of Latvian Fisheries Research Institute (LatFRI). Reproductive volume estimates derived by LatFRI (Plikshs et al. 1993) employed a contouring program ('Balthypsograph' prepared by Wulff and Andersson, University of Stockholm; details below) to estimate a volume of water whose hydrographic conditions were considered suitable for the development of cod Gadus morhua eggs, i.e. all water with a salinity of $>11$ psu and an oxygen concentration of $>2 \mathrm{ml}^{-1}$. These criteria were based on studies which established how interactions between cod-egg buoyancy, vertical distibution and oxygen concentration affect survival of cod eggs in the Baltic (Grauman 1973, Nissling \& Westin 1991, Bagge et al. 1994).

The hydrographic input data for the contouring program were collected at 1 site in the deepest part of each of the deep basins of the Baltic (Fig. 1). These sites were considered by Plikshs et al. (1993) to constitute only a rough approximation of conditions elsewhere in each basin, but they did allow estimates of reproductive volume to be calculated for long periods since the stations are frequently visited as part of various national and international monitoring programs.

The contouring software used for the volume estimations employs the hypsographic function for the Baltic proper derived from a gridded $5^{\prime} \times 5^{\prime}$ bathymetric database by Stigebrandt (1987) and Stigebrandt \& Wulff (1987). This function quantifies the volumes of water below horizontal surfaces at given depth levels. The depth levels at which horizontal surfaces are chosen for calculating water volumes are defined by the vertical profile of hydrographic data collected at the station in the basin. Hence, the volume of water between any 2 surfaces (e.g. those represented by the 11 psu and $2 \mathrm{ml}^{-1}$ oxygen levels) can be derived by assuming horizontal homogeneity on a basin-wide scale.

Estimates were made for various months of the year for the period 1952 to 1992 for all 4 basins; in addition, estimates are available for the southern and central Gotland Basin for the years 1993 to 1996. The raw hydrographic data used as input for the calculations by LatFRI represents national data collected by this insti- tute during all years from 1960 to present date. These data have not been deposited in international databases, e.g. International Council for the Exploration of the Sea (ICES) and the (HELCOM). For the years 1952 to 1959 , published ICES data from the annual volumes of Annales Biologiques and Bulletin Hydrographique were used for the Bornholm Basin and southern Gotland Basin calculations, data in Glowinska (1963) were used for the Gdansk Basin calculations, and the former USSR's Sea Hydrometeorological Annals (Baltic Sea) were used as the data source for the central Gotland Basin. The time series for the Gdansk Basin was extended beyond 1992 using data collected by Feldman et al. (1996) for the years 1993 and 1994.

Estimation methodology of Institute of Marine Science (IfMK). The hydrographic data set consists of measurements from 16 cruises carried out in the Bornholm Basin between May 1989 and April 1996 (Hinrichsen \& Wieland 1996). The station grid represents the Bornholm Basin enclosed by the $60 \mathrm{~m}$ isobath (Fig. 2). Two cruises conducted in 1989 covered only 21 stations, while during all other surveys 36 standard stations were covered with a mean horizontal resolution of $\sim 10 \mathrm{n}$ miles. The survey data were used to calculate the thickness of the spawning layer of Baltic cod, i.e. the vertical extension of the water body considered suitable for successful egg development (salinity $>11$ psu, oxygen $>2 \mathrm{ml}^{-1}$, temperature $>1.5^{\circ} \mathrm{C}$ ). These are the threshold levels for salinity and oxygen content derived in the previous subsection; a lower temperature boundary was considered in addition since low temperature limits the upper boundary of the water column suitable for egg development in years following severe winters (Wieland \& Jarre-Teichmann 1997).

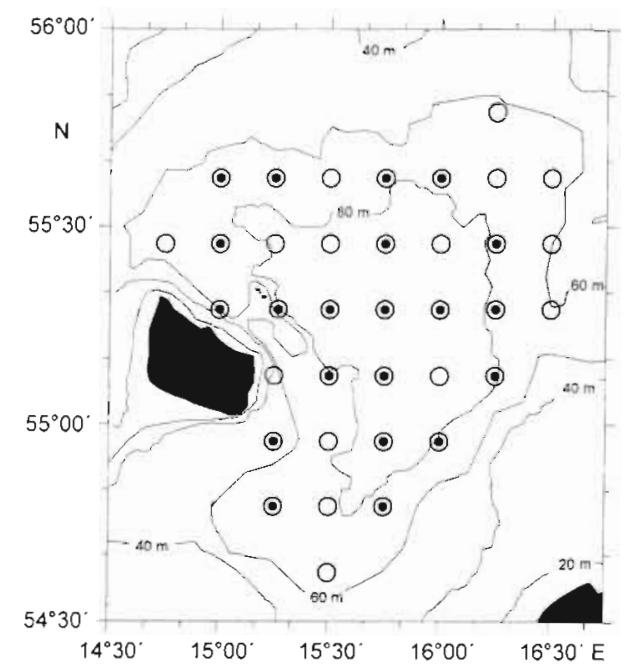

Fig. 2. Grid of hydrographic stations in Bornholm Basin used by University of Kiel research vessels for determining reproductive volumes during years 1989 ( 21 stations) and 1991-1996 (0: 36 stations) 
Horizontal fields of the thickness of the spawning layer were constructed by objective analysis (Bretherton et al. 1976) based on a standard statistical approach - the Gauss-Markov theorem - which yields an expression for the linear least-square error estimate of the variables. Objective analysis has the advantage that it can make use of statistical results (spatial covariance function of measurements) and assumptions concerning measurement noise and small-scale errors inferred from the observed data. Thus, at every single point an estimate can be given that depends linearly on the total number of measurements, i.e. a weighted sum of all observations (Bretherton et al. 1976). Objective analysis provides a smoothed version of the original measurements, with a tendency to underestimate the true field because of the specific assumptions involved in our treatment of measurement noise and small-scale signals unresolved by the observation array. Error estimates depend only on the statistics of the field, the noise level, and on the locations of the observation points, and not the measurements themselves. Hence, error maps can be calculated a priori for different array designs without reference to any particular data set.

As most of the experiments between 1989 and 1996 were designed to produce synoptic maps of the spawning layer, an accurate mapping technique was required. Applying the technique of objective analysis, a unit array configuration with $\mathrm{d} \lambda=2^{\prime}$ and $\mathrm{d} \varphi=1^{\prime}$ '(horizontal resolution $=\sim 1.8 \mathrm{~km}$ ) was provided based on the standard station-grid, whereby each grid point is representative of the thickness of the spawning layer centered around it. It was assumed that the error variance due to measurement errors and small-scale noise amounted to $15 \%$ of the total variance of the field. The reproductive volume of Baltic cod in the entire study area was calculated for the different surveys by simple horizontal integration of the fields of the thickness of the spawning layer, whereby only the area for which the expected root-meansquare (rms) error in the interpolation amounted to less than $20 \%$ was considered. The $20 \%$ rms error line was chosen because it is closely related to the $60 \mathrm{~m}$ isobath that corresponds to the horizontal limit of the cod egg distribution (Wieland 1995, Wieland \& Horbowa 1996).

For each of the 36 stations, the thickness of the spawning layer was compared with the total reproductive volume obtained for the 14 observation dates in the period 1991 to 1996 using linear regression analysis. To take into account reproductive volumes representing the extremely bad environmental conditions observed during the stagnation period in the late 1980s, data from the 2 additional surveys (1989, based on a 21 station grid: Fig. 2) were included in the analysis. The reproductive volumes for 1989 were estimated with reference to the unit array configuration based on the standard grici (36 stations).
Additional vertical profiles of salinity and temperature were obtained from the ICES hydrographic database for the period 1958 to 1996 . With these data, a time series of reproductive volumes was constructed using the relationship between single-point measurements of the thickness of the spawning layer in the central Bornholm Basin (HELCOM Stn BY5: Fig. 1) and the basin-wide estimates of the reproductive volume for the years 1989 and 1991 to 1996.

Data analyses. Each time series of reproductive volume was plotted to enable visual inspection of the raw data (Appendix 1; these data will also be available later in 2000 from http://www.ifm.uni-kiel.de/fi/STORE/welcome.htm). Frequency distributions were compared between areas, and 2-way analyses of variance were conducted to compare differences in reproductive volume between basins and months.

Intercomparison of 2 reproductive volume time series developed for Bornholm Basin. The 2 methodologies outlined in the first 2 subsections differ substantially in terms of approach, number of stations per basin, and source of the raw hydrographic data. If existing Latvian estimates are to be combined with new Kiel measurements to derive new time series for the Bornholm Basin, or for the entire Baltic, it is necessary that the series be comparable and, if necessary, appropriate calibrations applied. We compared the 2 reproductive volume series for the Bornholm Basin directly by regressing estimates from one series against the other on a month-specific basis and for all months combined. The years covered by this analysis were 1958 to 1992 . If the 2 series are directly comparable, the slope and intercept for these regression models should equal 1 and 0 , respectively, and the explained variation $\left(\mathrm{R}^{2}\right)$ should be highly significant $(p<0.05)$. Deviations from the expected slope and intercept values indicate bias of one series relative to the other. We used the output regression models to update the Bornholm Basin time series prepared by Plikshs et al. (1993) and fill in missing data points.

\section{RESULTS}

\section{Overall statistical characteristics and between-basin spatial difierences}

The time series of reproductive volume in each of the basins show wide (10-to 20 -fold) multi-year variability (Fig. 3). The site with the largest and least variable reproductive volume (in terms of coefficient of variation, $\mathrm{SD} / \mathrm{mean}$ ) was the Bornholm Basin (Table 1). The most variable site was the central Gotland Basin. The frequency distributions of all observations recorded in all 


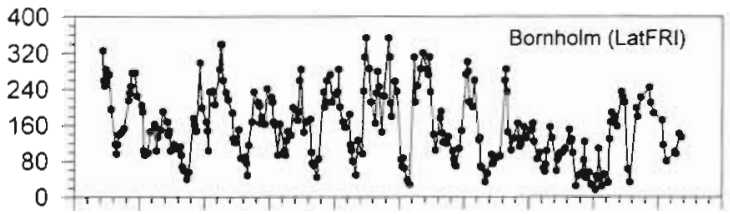

19501955196019651970197519801985199019952000

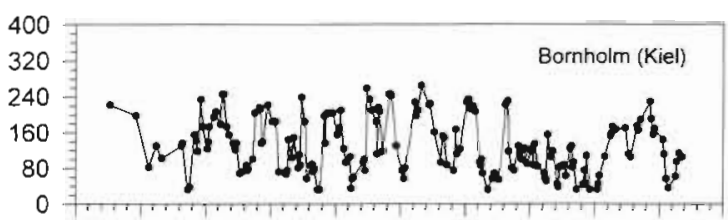

19501955196019651970197519801985199019952000
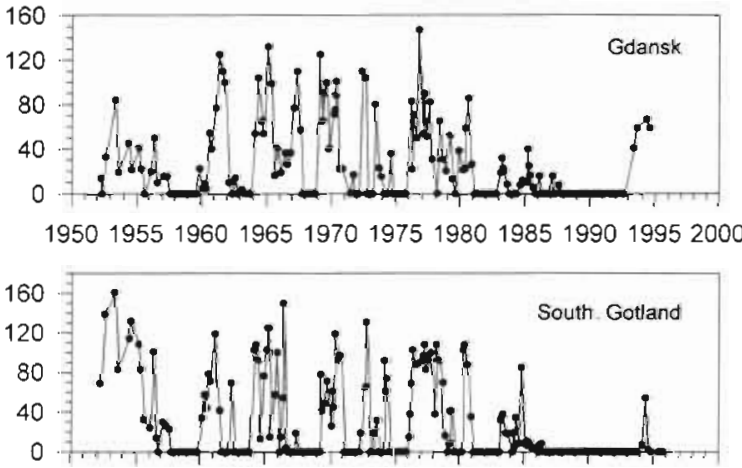

19501955196019651970197519801985199019952000

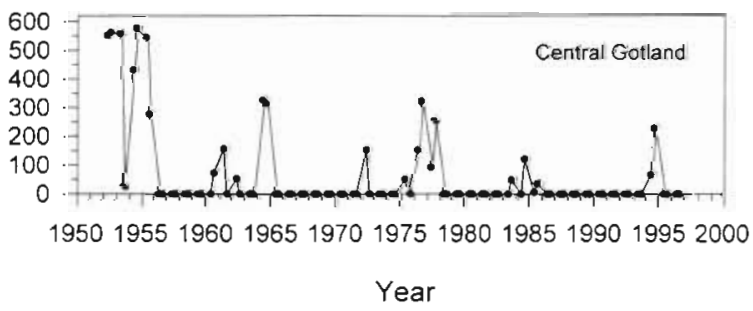

Fig. 3. Time series of reproductive volumes for each spawning site. 2 series of estimates for the Bornholm Basin were prepared by Plikshs et al. (1993: LatFRI [LatFRI: Latvian Fisheries Institute]) and Hinrichsen \& Wieland (1996: Kiel). Time series for the other basins were prepared by Plikshs et al. (1993); however, Gdansk Basin data from 1993 onwards were estimated semi-quantitatively from contour plots of Feldman et al. (1996)

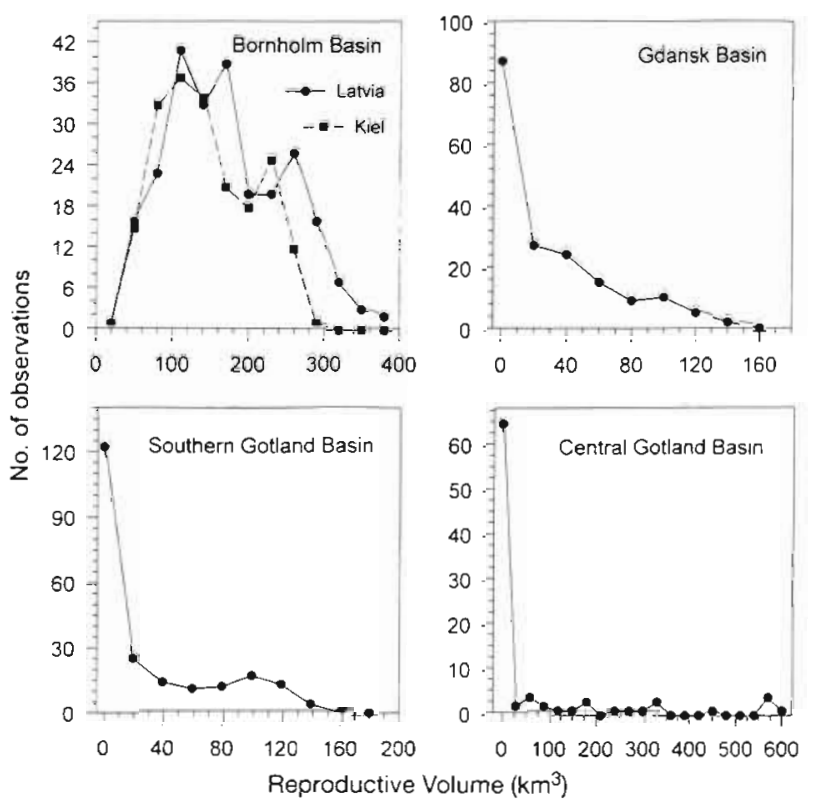

Fig. 4. Frequency distributions of reproductive volumes in each of the 4 deep basins of the Baltic Sea. Time periods covered by data and summary statistics are given in Table 1

months at each of the sites show that 3 of the 4 series are skewed towards zero (Fig. 4). Median values in the 2 northeasternmost basins were zero (Table 1 ).

Two-way ANOVA (main effects: basin and month) revealed basin to be the dominant effect. The basin effect explained $60 \%$ of the variance in reproductive volumes $(p<0.0001)$ for the months when data were available for only the Bornholm, Gdansk and southern Gotland basins; the month effect was insignificant ( $\mathrm{p}=$ 0.61 ). During the months when data were available for the Central Gotland Basin (May and August), the basin effect explained $23 \%$ of the variance in reproductive volume $(p<0.0001)$ and the month effect was insignificant $(p=0.28)$. In both cases, the Bornholm Basin had the highest mean reproductive volume $(p>0.05$; GT2 multiple-comparison test: SAS Institute Inc.

Table 1. Summary statistics of raw reproductive volume $\left(\mathrm{km}^{3}\right)$ data for each main spawning basin of cod Gadus morhua in central Baltic Sea. LatFRI: Latvian Fisheries Research Institute; AtlantNIRO: Atlantic Scientific Research Institute of Marine Fisheries and Oceanography

\begin{tabular}{|lcccc|}
\hline Basin & Time period & N & Mean (SD) & Median \\
\hline Bornholm (LatFRI) & $1952-1992$ & 246 & $158(78)$ & 147 \\
Bornholm(Kiel) & $1958-1996$ & 197 & $130(62)$ & 122 \\
Gdansk (LatFRI \& AtlantNIRO) & $1952-1994$ & 187 & $25(35)$ & 8.5 \\
Southern Gotland (LatFRI) & $1952-1995$ & 228 & $28(41)$ & 0 \\
Central Gotland (LatFRI) & $1952-1996$ & 90 & $66(149)$ & 0 \\
\hline
\end{tabular}


Table 2. Total mean (SE) reproductive volume (Vol) in Baltic Sea and mean (SE) monthly proportion in Bornholm Basin (Bornholm \%) during 1952 to 1992. Data are LatFRI estimates. May and August data include central Gotland Basin, which is excluded from results for other months. (N for May and August: number of years when measurements available for all basins; $N$ for other months: number of years when data available for Bornholm. Gdansk and southern Gotland Basins only')

\begin{tabular}{|llll|}
\hline Month & N & Vol $\left(\mathrm{km}^{3}\right)$ & Bornholm \% \\
\hline Feb & 36 & $204(20)$ & $86(0.03)$ \\
Mar & 14 & $188(37)$ & $87(0.04)$ \\
Apr & 16 & $237(35)$ & $82(0.04)$ \\
May & 40 & $294(37)$ & $70(0.04)$ \\
Aug & 41 & $261(37)$ & $74(0.04)$ \\
Oct & 35 & $190(20)$ & $85(0.03)$ \\
\hline
\end{tabular}

We repeated this analysis of variance using nonparametric statistical methods because some of the frequency distributions of the reproductive volumes departed from normal because of a high frequency of zero values. However, the results of 1 -way nonparametric ANOVAs for differences between basins were similar to those of the parametric analysis (KruskalWallis chi-square test: $p<0.0001$ for sets of months with and without the central Gotland data)

The average monthly total reproductive volume in the Baltic Sea, as calculated from the LatFRI estimates for 1952 to 1992, and the fraction contained in the Bornholm Basin ranged from 188 to $294 \mathrm{~km}^{3}$ and 70 to $87 \%$, respectively (Table 2). For the months of May and August, when estimates for the central Gotland Basin are available, the Bornholm Basin represents on average 70 to $74 \%$ (standard error $=4 \%$ ) of the total reproductive volume in the Baltic Sea. For the other months, which exclude the contribution of the central Gotland Basin, the Bornholm Basin contains 82 to $87 \%$ of the reproductive volume.

\section{Assessment of horizontal homogeneity within a basin}

The process of estimating the cod reproductive volume according to discrete values of the spawninglayer thickness can be facilitated by use of a simplelinear regression model. Fig. 5 shows the horizontal distribution of the $\mathrm{R}^{2}$ values for the cross correlation between spawning layer thickness of a single station and corresponding cod reproductive volume based on the spatial coverage of 36 stations. Most of the locations displayed a high correlation of single-point observations of the spawning-layer thickness with horizontally integrated quantities of its water volume. For

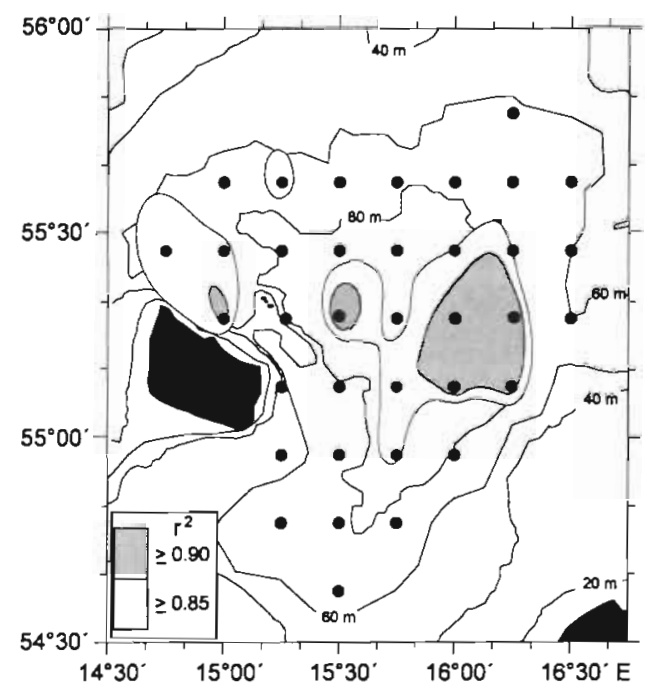

Fig. 5. $\mathrm{R}^{2}$ values for cross-correlation between thickness of spawning layer and reproductive volume of cod based on a 36 station standard grid (1991 to 1996) in the Bornholm Basin

the northern part of the Bornholm Basin, the overall structure of the correlations did not change dramatically. It is apparent that highest values for $\mathrm{R}^{2}$ occurred in the central deep part of the basin, whereas the correlations tend to decrease with decreasing water depth. Additionally, relatively high correlations were found for the Bornholm Gat region, i.e. the northwestern part of the study area. Generally, weaker correlations were found for the southern part of the Bornholm Basin with water depths $<80 \mathrm{~m}$

Linear regression models for 4 locations in the central Bornholm Basin yielded correlations with $\mathrm{R}^{2} \geq 0.89$ (including the data from 1989 based on the reduced station grid: Fig. 6). For the observation dates in the period 1989 to 1996, the reproductive volume as estimated by basin-wide integration ranged from $8 \mathrm{~km}^{3}$ (June 1989) to $229 \mathrm{~km}^{3}$ (April 1994). The standard error of the basinwide reproductive volume significantly increased with the mean (Fig 7). The corresponding maximum values for the thickness of the spawning layer varied considerably between the 4 stations. The highest value of $42 \mathrm{~m}$ was recorded in the center of the study area, followed by $33 \mathrm{~m}$ observed at a station located approximately $10 \mathrm{n}$ miles further to the east. Close to the entrance to the Stolpe trench and $\sim 12 \mathrm{n}$ miles southeast from the central station, the maxima of the thickness of the spawning layer amounted to only 21 and $27 \mathrm{~m}$, respectively. However, for all of these stations there was close correlation between the reproductive volume and the thickness of the spawning layer.

We therefore used one of these regression models (Fig. 6) to construct a time series of reproductive volumes from 1958 to 1996 . The model we chose was that 


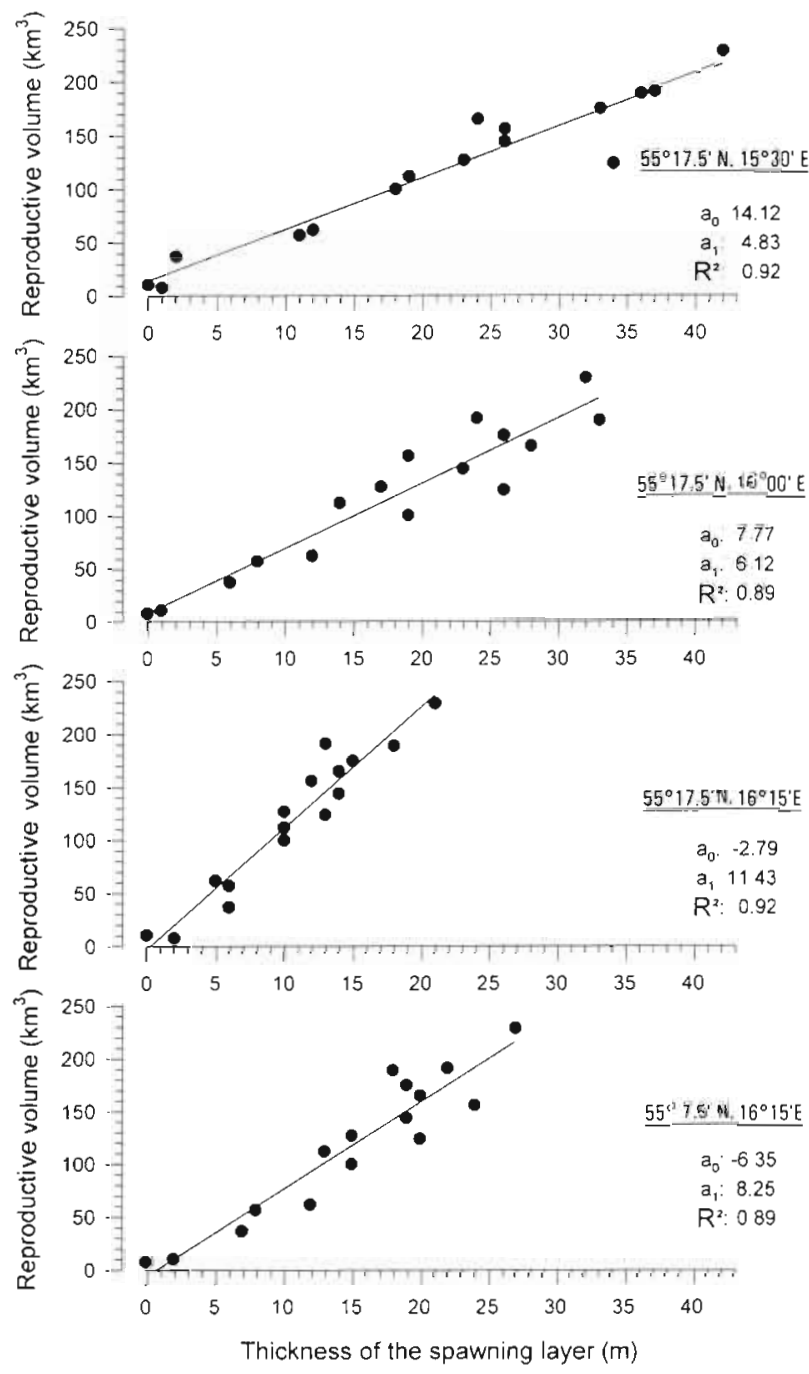

Fig. 6. Regression models for correlation of thickness of the spawning layer at 4 stations with basin-wide reproductive volume. (… $95 \%$ confidence limits

for the station located at $55^{\circ} 17.5^{\prime} \mathrm{N}, 16^{\circ} 00^{\prime} \mathrm{E}$. This station was the most frequently visited location (total number of observations $=466$ ) during the recent decades; all single-point measurements were considered if they were $<10 \mathrm{~km}$ from the nominal geographical position represented by the HELCOM international monitoring Stn BY5 $\left(55^{\circ} 15^{\prime} \mathrm{N}, 16^{\circ} 00^{\prime} \mathrm{E}\right)$. The time series of reproductive volumes based on this station and calibration model were subsequently used for comparison with the Latvian estimates (see following subsection).

\section{Intercomparison of 2 time series of reproductive volume for Bornholm Basin}

The LatFRI time series spans the period 1952 to 1992 and has more observations $(N=246)$ than the Kiel

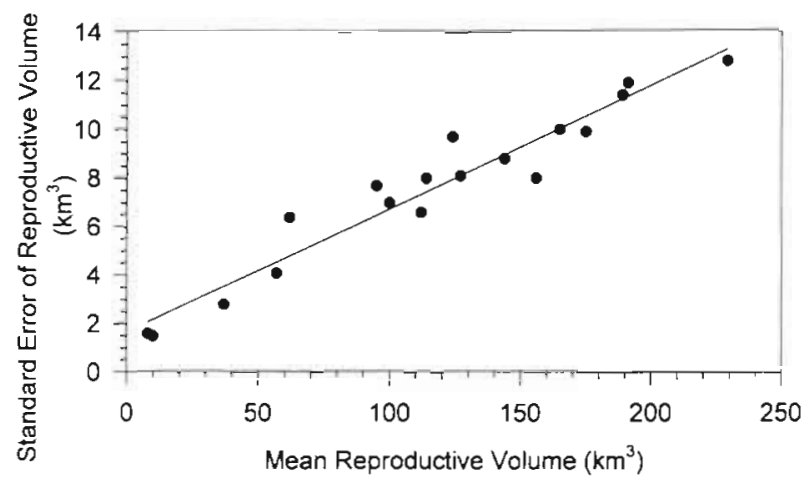

Fig. 7. Standard error of reproductive volumes estimated by objective analysis of a 36 station hydrographic grid for different mean levels of reproductive volume

series ( $N=197$ ), which began later (1958) and is ongoing (Table 1). Visual inspection of the time series plots suggests that the peaks and troughs in both series generally coincide (Fig. 3). However the Latvian series tends to have somewhat higher peaks than the Kiel series.

The frequency distribution of the values for each of the Bornholm Basin series suggests that the LatFRI estimates tend to be larger and that both series are slightly abnormal. A Student's t-test and variance-ratio test showed that the mean and variance of the LatFRI series were both significantly larger than the Kiel series ( $t$-test for means: $\mathrm{p}<0.0001$; F-ratio test for variances: $p=0.0009$ ). A 2 -way ANOVA with month and institute as effects showed that only the institute effect was significant $(\mathrm{p}<0.0001)$.

The Kiel estimates obtained by objective analysis are accompanied by estimates of their variability. A comparison of the variability of these estimates to the mean value shows that the variance increases significantly with the mean (Fig. 7). The Latvian estimates have no such error estimates.

Month-specific regression analyses between the 2 data series generally showed a strong correspondence between estimates (Table 3, Fig. 8). All regressions were highly significant $(\mathrm{p}<0.0001)$ and the explained variation $\left(R^{2}\right)$ was 44 to $82 \%$. None of the slopes differed significantly from 1. However, the intercepts were close to being significantly different from zero for some months, and the intercept was highly significant when all months were combined for an overall analysis (Fig. 8). Intercept values ranged from -15.8 to 47.4 for individual months, and equalled 24.5 for the 'all months combined' model. The residual mean square error (a measure of how large an individual observation might deviate from the average pattern) for the 'all months combined' model is ca $43.6 \mathrm{~km}^{3}$.

Using the month-specific models, we then updated the Latvian time series for the Bornholm Basin for the 
Table 3. Statistical results of comparisons of 2 sets of reproductive volume $(R V)$ estimates. Regression model fitted was $R V_{\text {Latva }}=$ $a+b \cdot R V_{\text {kiel }}$ RMSE: residual mean square error of the observed estimates from predictions made by the regression model

\begin{tabular}{|lcccccrrr|}
\hline Month & $R^{2}$ & $N$ & $p$ & RMSE & $a(\mathrm{SE})$ & $\mathrm{p}$ & $b(\mathrm{SE})$ & $\mathrm{p}$ \\
\hline Feb & 0.80 & 31 & $<0.0001$ & 34.9 & $19.8(15.2)$ & 0.2034 & $1.14(0.11)$ & $<0.0001$ \\
Mar & 0.72 & 32 & $<0.0001$ & 40.4 & $25.1(16.7)$ & 0.1422 & $1.04(0.12)$ & $<0.0001$ \\
Apr & 0.44 & 32 & $<0.0001$ & 65.6 & $47.4(26.0)$ & 0.0789 & $0.86(0.18)$ & $<0.0001$ \\
May & 0.82 & 30 & $<0.0001$ & 33.0 & $-15.8(15.9)$ & 0.3281 & $1.18(0.10)$ & $<0.0001$ \\
Aug & 0.80 & 34 & $<0.0001$ & 36.6 & $18.3(13.9)$ & 0.1953 & $1.08(0.10)$ & $<0.0001$ \\
Oct & 0.73 & 22 & $<0.0001$ & 39.4 & $36.2(17.0)$ & 0.0454 & $0.91(0.12)$ & $<0.0001$ \\
All months & 0.68 & 181 & $<0.0001$ & 43.6 & $24.5(7.5)$ & $<0.0001$ & $1.02(0.05)$ & $<0.0001$ \\
Combined & & & & & & & & \\
\hline
\end{tabular}

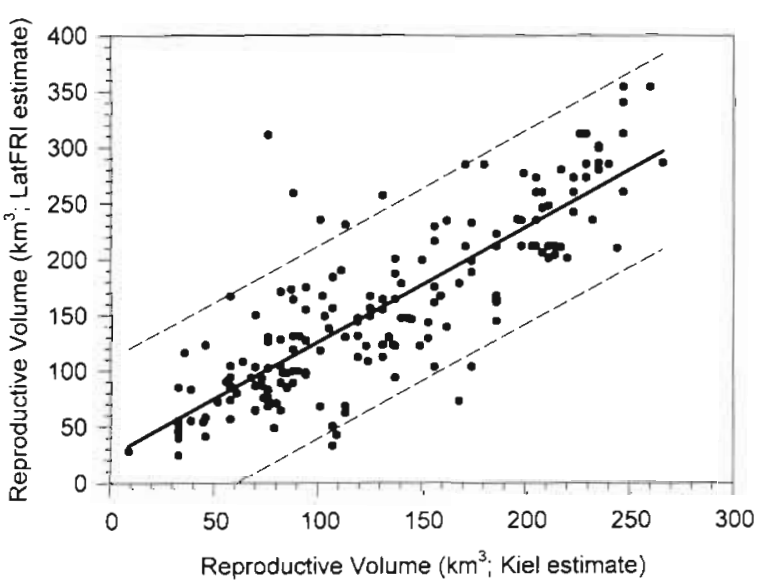

Fig. 8. Regression model comparing reproductive volumes in the Bornholm Basin for all months for which data were available during 1958-1992. Reproductive volumes were estimated by 2 different methods employing different input hydrographic datasets (see Table 3 for statistical results); (----) $95 \%$ prediction limits

years 1993 to 1996 based on the measured Kiel estimates. The proximate LatFRI estimates for these years are shown in Fig. 3.

\section{DISCUSSION}

\section{Time series development and methodological comparisons}

Gadus morhua spawn in the Baltic Sea in welldefined areas, and the vertical distribution of their eggs is becoming increasingly better described (Vieland \& Jarre-Teichmann 1997). In addition, the transport of eggs away from at least 1 of these spawning sites is likely to be limited under the most frequent hydrographic situations prevailing in the Baltic (Wieland 1995, Hinrichsen et al. 1997). In general, these 2 circumstances (known spawning site and high pro- bability of geographic retention of the eggs) greatly facilitate operational definitions of the size and quality of the habitat occupied by fish eggs, particularly in comparisons with fish populations in areas where locations of spawning sites are variable (e.g. deYoung \& Rose 1993, Anderson \& Dalley 1997) or where boundaries surrounding the spawning site are much more dynamic (e.g. deYoung \& Davidson 1994, Heath \& Gallego 1997).

Our calculations and analyses show that under such circumstances it is possible to quantify the volume of water in which cod eggs can develop successfully in the Baltic Sea. These volume estimates should be considered as approximations because they assume 100 and $0 \%$ egg survival at oxygen concentrations above and below $2 \mathrm{ml}^{-1}$, respectively. In reality, laboratory experiments show that cod egg survival increases with increasing oxygen concentration in the range 2 to $5 \mathrm{ml}^{-1}$, and varies independently of oxygen concentration in the range 5 to $9 \mathrm{ml}^{-1}$ (Wieland et al. 1994). Hence, our volume estimates probably overestimate the true volumes which ensure cod egg survival; in nature, therefore the volume of water that ensures cod egg survival with high probability will be somewhat smaller than the volumes estimated by our analyses.

Our analyses indicate that a carefully chosen monitoring site can represent conditions throughout an entire basin, at least for the purpose of estimating reproductive volumes. The locations of individual stations which gave the best correlation with the whole-grid volume estimates were those located in the central deep part of the basin. Correlations between reproductive volumes estimated by objective analysis using a 36-station grid as input and reproductive volumes estimated by extrapolating spawning layer thickness at 1 station throughout the basin were highly significant over a wide range of oxygen conditions in the Bornholm Basin. This relationship was used to develop an extended time series to enable comparison with an independent set of observations by Plikshs et al. (1993).

The comparison of the IfMK data with the independent set of observations developed by Plikshs et al. 
(1993) showed that both series of estimates for the Bornholm Basin were similar, thereby giving confidence that both series reveal the major patterns of variability within the Bornholm Basin. In our analysis the difference in reproductive volume estimates between methods was similar for all ranges of reproductive volume (i.e. slope not significantly different from 1). We conclude that single-point estimates from the central deep part of the Bornholm Basin can produce reasonable estimates of the size and quality of habitat available for cod eggs. We also conclude that the strong relationship between the 2 series facilitates intercomparisons, the interpolation of missing values, and the construction of intact series into the future. Given the changes in sampling effort during the 1990s (see 'Introduction'), this could be useful for processmodelling studies of egg survival and recruitment.

The intercomparison of the 2 data series revealed some differences as a function of the time of year used in the comparison. For example, the explained variation was usually 70 to $80 \%$ for each month considered, except for April, when it was only $44 \%$. We have no obvious explanation for the higher variability in April. In addition, within each monthly comparison there were some noticeable outliers. These could occur for example if the hydrographic data were collected at different times within the month and hydrographic conditions changed during the intervening period (e.g. initiation of an inflow from the western Baltic). Other sources of error contributing to the residual variability would include differences in the vertical positions of iso- and oxypycnals relative to the depth layers sampled during the research surveys.

The objective-analysis methodology used to produce the Kiel reproductive volume estimates from the 36-station grid yields a measure of reliability of the observed estimates. The standard error of a reproductive volume estimate obtained from objective analysis increases with the mean. The variance-mean relationship suggests that it may be necessary to sample at more stations when there are high oxygen levels in the basin, when the same degree of reproductive volume accuracy is desired. A larger spatial coverage under high oxygen conditions appears necessary to ensure that all oxygenated areas within the basin are sampled.

It is unclear whether the methodological comparisons for reproductive volume estimation in the Bornholm Basin would apply to the other spawning basins in the Baltic Sea. For example the environmental heterogeneity within each of the other basins may differ from that in the Bornholm Basin. Our analyses suggest that environmental heterogeneity in the Bornholm Basin is relatively low, since 1 carefully-chosen station can often approximate conditions throughout the basin. However, in either the Gdansk or Gotland
Basins, conditions may be more heterogeneous for example because of differences in hydrographic processes and bottom topography (Feldman et al. 1996, Zezera \& Zezera 1997). In such cases, single-station estimates of reproductive volume may be less representative of basin-wide conditions than is the case in the Bornholm Basin, and several stations might be necessary to provide reliable estimates. It would therefore be desirable to repeat the comparisons made in the Bornholm Basin in the remaining spawning areas.

\section{Spatial and temporal heterogeneity in reproductive volumes}

Our analyses of spatial and temporal heterogeneity of reproductive volumes quantify what many colleagues in the Baltic fisheries and oceanographic communities have recognized for years: conditions for successful cod-egg development are most likely to be found in the Bornholm Basin. Volumes in this basin were relatively high and less variable in comparison with volumes in the other basins. However, exceptions to this broad pattern do occur, particularly between years. For example, during the longest recorded period without a major inflow of North Sea water (1983 to 1993: Schinke \& Matthäus 1998), reproductive volumes in this basin became very low. In addition, oxygen-renewal events (e.g. inflows) can rapidly and significantly improve conditions in all basins (Matthäus \& Lass 1995).

These observations suggest that a detailed analysis of the temporal variability in reproductive volumes would be insightful. Some preliminary studies of the temporal variability in the Bornholm Basin using the Latvian time series (Plikshs et al. 1993) have shown that reproductive volumes vary seasonally (MacKenzie et al. 1996), and that these variations may be related to water temperature and oceanographic production processes (MacKenzie et al. 1996). The seasonal variations in reproductive volume are probably associated with seasonal variations in both oxygen concentrations (Matthäus 1978, Wieland 1995) and salinity, which is influenced by freshwater runoff to the Baltic (Viitasalo et al. 1995, Schinke \& Matthäus 1998). In addition to seasonal variations in reproductive volumes, processes, such as eutrophication (Rahm et al. 1996, Wasmund et al. 1998), that operate at longer time scales could contribute to multi-annual variability. The present compilation of intercalibrated and validated data series will enable these variations to be investigated with greater confidence in the future.

The impact of the spatial and temporal heterogeneity in conditions at cod spawning sites on egg survival and recruitment may be significant. The temporal (interannual) variations in total reproductive volume appear to 
have a significant impact on recruitment, and it is inferred that this correlation is due to low egg survival when total reproductive volume is small (Plikshs et al. 1993, Sparholt 1996, Jarre-Teichman et al in press). In addition, the spatial variations within a year will also probably be important. Jarre-Teichman et al. (in press) have noted that much (60 to $80 \%$ : ICES 1997) of the spawning stock was located in Subdivisions 26 and 28 in the early $1980 \mathrm{~s}$, when reproductive volumes in these same areas were essentially absent (Fig. 3), and that this may have contributed to the rapid decline in re- cruitment despite near-record high levels of spawning biomass. These observations suggest that heterogeneity at scales smaller than the entire management area or stock unit may influence egg survival or recruitment.

Acknowledgements. This work was partly supported by a grant from the European Union (AIR2-CT94-1226, Baltic Cod Recruitment Project). We thank Dr Henrik Sparholt (Fisheries Assessment Scientist, ICES) and 3 anonymous reviewers for their useful and constructive comments on an earlier version of this manuscript. We thank Dr Harry Dooley (ICES Hydrographer) for providing hydrographic data from the ICES database.

Appendix 1. Raw reproductive volume $\left(\mathrm{km}^{3}\right)$ data used in intercalibration and comparative analyses; missing value code $=-99$

\begin{tabular}{|c|c|c|c|c|c|c|}
\hline Year & Feb & Mar & A.pr & May & Aug & Oct \\
\hline 1952 & 325 & 259 & 247 & 284 & 272 & 195 \\
\hline 1953 & 117 & 96 & 117 & 139 & 144 & 153 \\
\hline 1954 & 215 & 231 & 246 & 276 & 276 & 224 \\
\hline 1955 & 204 & 190 & 103 & 93.5 & 98.1 & 145 \\
\hline 1956 & 162 & 155 & 103 & 133 & 149 & 190 \\
\hline 1957 & 167 & 138 & 147 & 103 & 117 & 108 \\
\hline 1958 & 112 & 93.5 & 67.2 & 59 & 39.7 & 55.1 \\
\hline 1959 & 175 & 161 & 147 & 147 & 298 & 198 \\
\hline 1960 & 167 & 147 & 103 & 234 & 235 & 205 \\
\hline 1961 & 284 & 339 & 339 & 259 & 232 & 216 \\
\hline 1962 & 187 & 130 & 122 & 122 & 150 & 86.5 \\
\hline 1963 & 89 & 75.5 & 48.5 & 115 & 167 & 234 \\
\hline 1964 & 210 & 203 & 164 & 178 & 162 & 241 \\
\hline 1965 & 222 & 211 & 167 & 161 & 93.1 & 162 \\
\hline 1966 & 103 & 93.4 & 126 & 146 & 138 & 199 \\
\hline 1967 & 171 & 190 & 259 & 284 & 144 & 167 \\
\hline 1968 & 173 & 99.5 & 75.5 & 70.7 & 43.7 & 85 \\
\hline 1969 & 234 & 200 & 211 & 259 & 272 & 211 \\
\hline 1970 & 229 & 234 & 284 & 200 & 167 & 155 \\
\hline 1971 & 184 & 116 & 104 & 79.7 & 48.6 & 126 \\
\hline 1972 & 96 & 235.2 & 311 & 353 & 285 & 211 \\
\hline 1973 & 164 & 231 & 279 & 245 & 144 & 224 \\
\hline 1974 & 353 & 311 & 209 & 179 & 257 & 235 \\
\hline 1975 & 83 & 67.8 & 86.5 & 64.3 & 38 & 28.1 \\
\hline 1976 & 311 & 211 & 247 & 247 & 285 & 320 \\
\hline 1977 & 284 & 272 & 311 & 234 & 139 & 104 \\
\hline 1978 & 175 & 190 & 143 & 122 & 119 & 134 \\
\hline 1979 & 102 & 84.5 & 72.3 & 68.2 & 108 & 147 \\
\hline 1980 & 272 & 300 & 279 & 211 & 200 & 259 \\
\hline 1981 & 127 & 131 & 67.8 & 64.9 & 33.3 & 51.8 \\
\hline 1982 & 94 & 73.6 & 86.3 & 84.6 & 89.8 & 91.1 \\
\hline 1983 & 259 & 284 & 234 & 144 & 104 & 130 \\
\hline 1984 & 164 & 130 & 112 & 118 & 156 & 131 \\
\hline 1985 & 147 & 149 & 164 & 123 & 84.4 & 98.1 \\
\hline 1986 & 64 & 56.6 & 71.9 & 103 & 156 & 131 \\
\hline 1987 & 58 & 82.9 & 89 & 97.6 & 99.5 & 108 \\
\hline 1988 & 150 & 123 & 128 & 98.1 & 24.4 & 46.8 \\
\hline 1989 & 54 & 82.2 & 123 & 42.5 & 55.1 & 27.4 \\
\hline 1990 & 16 & 46.3 & 41.17 & 108 & 24.4 & 50.1 \\
\hline 1991 & 32 & 129 & 167 & 188 & 178 & 1.57 \\
\hline 1992 & 234 & 222 & 211 & 211 & 62 & 32.9 \\
\hline 1993 & -99 & -99 & 198 & 179 & 222 & -99 \\
\hline 1994 & -99 & -99 & 244 & 210 & 187 & -99 \\
\hline 1995 & -99 & -99 & 171 & 116 & 80 & -99 \\
\hline 1996 & -99 & -99 & 101 & 96 & 141 & 133 \\
\hline
\end{tabular}




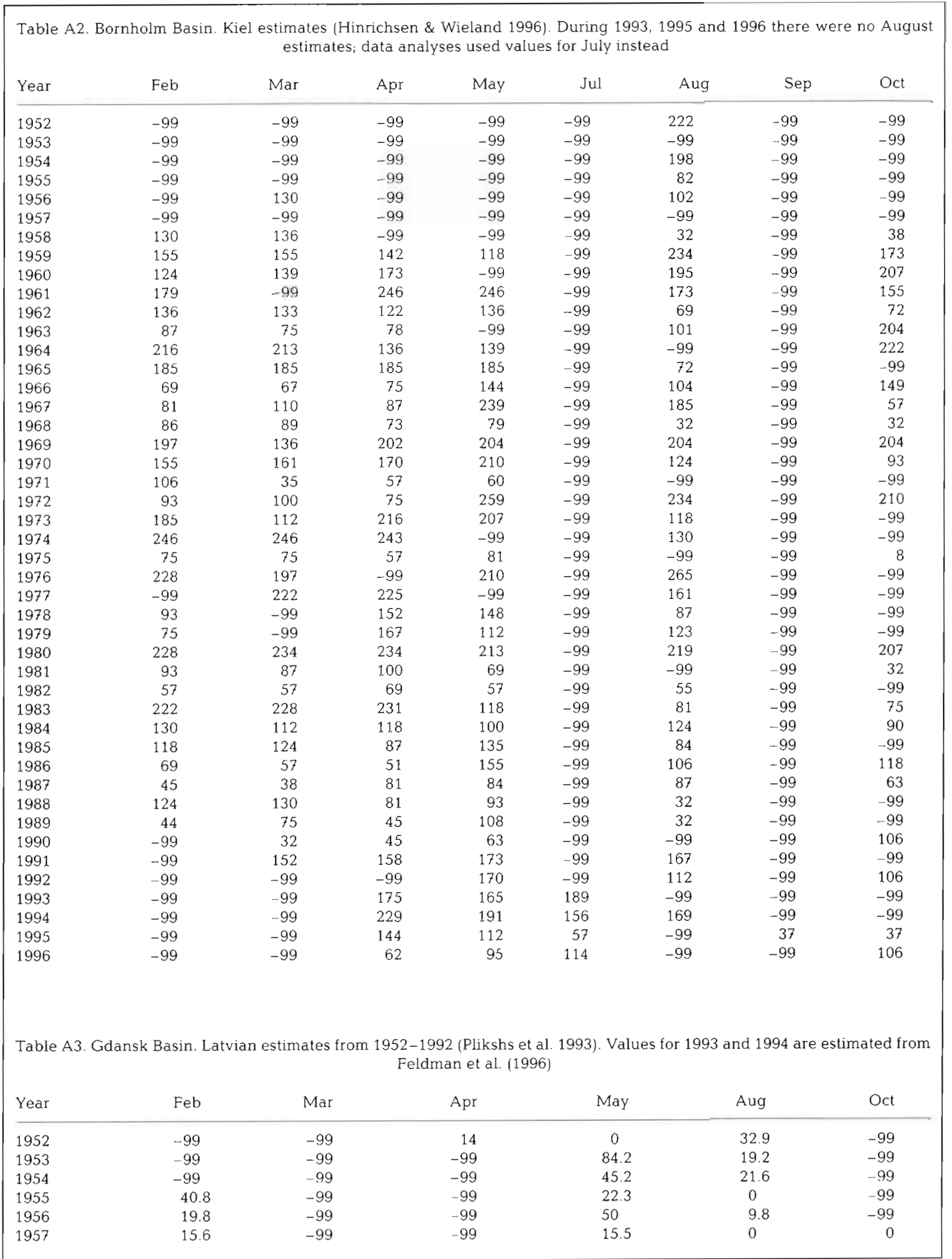




\begin{tabular}{|c|c|c|c|c|c|c|}
\hline \multicolumn{7}{|c|}{ Table A3 (continued) } \\
\hline Year & Feb & Mar & Apr & May & Aug & Oct \\
\hline 1958 & 0 & -99 & -99 & 0 & 0 & 0 \\
\hline 1959 & 0 & -99 & -99 & 0 & 0 & 22 \\
\hline 1960 & 5 & -99 & 9 & 5.07 & 54.4 & 40 \\
\hline 1961 & 77 & -99 & -99 & 125 & 110 & 100 \\
\hline 1962 & 10 & -99 & -99 & 0 & 14.3 & 0 \\
\hline 1963 & 4 & -99 & -99 & 0 & 0 & 0 \\
\hline 1964 & 54 & -99 & -99 & 104 & 65.2 & 54 \\
\hline 1965 & 132 & -99 & -99 & 98.8 & 16.2 & 41 \\
\hline 1966 & 19 & -99 & -99 & 36 & 26.3 & 36 \\
\hline 1967 & 77 & -99 & -99 & 110 & 57.3 & 0 \\
\hline 1968 & 0 & -99 & -99 & 0 & 0 & 0 \\
\hline 1969 & 125 & -99 & 65 & 90.1 & 99.7 & 40 \\
\hline 1970 & 71 & 75 & 88 & 101 & 22.2 & 22 \\
\hline 1971 & -99 & -99 & -99 & 0 & 16.4 & 0 \\
\hline 1972 & 0 & -99 & -99 & 110 & 104 & 0 \\
\hline 1973 & 0 & 0 & -99 & 80.3 & 22.5 & 15 \\
\hline 1974 & 0 & -99 & 0 & 0 & 36 & 0 \\
\hline 1975 & 0 & 0 & 0 & 0 & 0 & 0 \\
\hline 1976 & -99 & 83 & 22 & 70.9 & 49.9 & 147 \\
\hline 1977 & 54 & 90 & 65 & 51.5 & 82.4 & 31 \\
\hline 1978 & 0 & -99 & -99 & 65.3 & 30.4 & 20 \\
\hline 1979 & 52 & -99 & -99 & 13.3 & 0 & 38 \\
\hline 1980 & 21 & -99 & 22 & 58.7 & 85.7 & 26 \\
\hline 1981 & 0 & -99 & -99 & 0 & 0 & 0 \\
\hline 1982 & 0 & 0 & -99 & 0 & 0 & 0 \\
\hline 1983 & 19 & 32 & 23 & 20.2 & 8.5 & 0 \\
\hline 1984 & 0 & 0 & -99 & 0 & 7.8 & 12 \\
\hline 1985 & 10 & 40 & 25 & 16.4 & 5.4 & 0 \\
\hline 1986 & 16 & 0 & 0 & 0 & 0 & 0 \\
\hline 1987 & 16 & 0 & 0 & 0 & 7.8 & 0 \\
\hline 1988 & 0 & 0 & 0 & 0 & 0 & 0 \\
\hline 1989 & 0 & 0 & 0 & 0 & 0 & 0 \\
\hline 1990 & 0 & 0 & 0 & 0 & 0 & 0 \\
\hline 1991 & 0 & -99 & -99 & 0 & 0 & 0 \\
\hline 1992 & 0 & -99 & -99 & 0 & 0 & -99 \\
\hline 1993 & -99 & -99 & -99 & 41 & 59 & -99 \\
\hline 1994 & -99 & -99 & -99 & 67 & 59 & -99 \\
\hline 1995 & -99 & -99 & -99 & -99 & -99 & -99 \\
\hline 1996 & -99 & -99 & -99 & -99 & -99 & -99 \\
\hline \multicolumn{7}{|l|}{ Table } \\
\hline Year & Feb & Mar & Apr & May & Aug & Oct \\
\hline 1952 & -99 & -99 & 69 & -99 & 139 & -99 \\
\hline 1953 & -99 & -99 & -99 & 161 & 83.1 & -99 \\
\hline 1954 & -99 & -99 & -99 & 114 & 132 & -99 \\
\hline 1955 & 108 & -99 & -99 & 83.1 & 32.5 & -99 \\
\hline 1956 & 24 & -99 & -99 & 101 & 13.8 & 0 \\
\hline 1957 & 30 & -99 & -99 & 26.4 & 22.7 & 0 \\
\hline 1958 & 0 & -99 & -99 & 0 & 0 & 0 \\
\hline 1959 & 0 & -99 & -99 & 0 & 0 & 0 \\
\hline 1960 & 34 & 57 & 57 & 43.9 & 78.5 & 71 \\
\hline 1961 & 119 & -99 & -99 & 41.4 & 0 & 0 \\
\hline 1964 & 103 & 103 & 108 & 92.4 & 13.2 & 76 \\
\hline 1965 & 103 & 125 & 125 & 14.9 & 57 & 100 \\
\hline 1966 & 0 & 15 & 54 & 150 & 4.3 & 0 \\
\hline 1967 & 0 & 0 & 0 & 18.7 & 0 & 0 \\
\hline
\end{tabular}




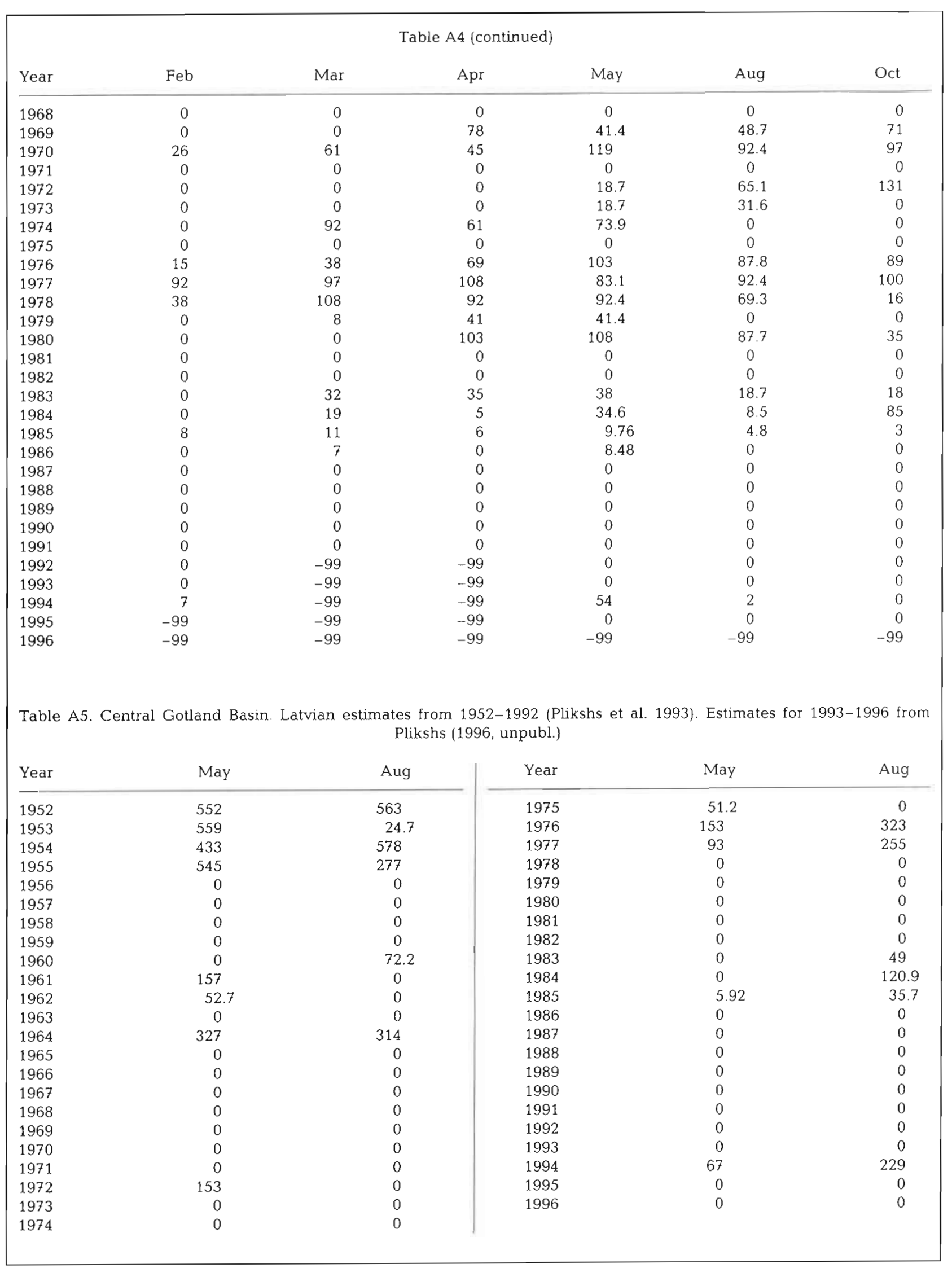




\section{LITERATURE CITED}

Anderson JT, Dalley EL (1997) Spawning and year-class strength of northern cod (Gadus morhua) as measured by pelagic juvenile cod surveys, 1991-1994. Can J Fish Aquat Sci 54(1):158-16?

Bagge O, Thurow F, Steffensen E, Bay J (1994) The Baltic cod. Dana 10:1-28

Bretherton FP, Davis RE, Fandry CB (1976) A technique for objective analysis and design of oceanographic experiments applied to MODE-73. Deep-Sea Res 23:559-582

deYoung $B$, Davidson F (1994) Modelling retention of cod eggs and larvae (Gadus morhua L.) on the Newfoundland Shelf ICES Mar Sci Symp 198:346-355

de Young B, Rose GA (1993) On recruitment and distribution of Atlantic cod (Gadus morhua) off Newfoundland. Can J Fish Aquat Sci 50:2729-2741

Feldman VN, Nazarov NA, Zezera AS, Zezera ES (1996) Salinity/oxygen regime of water in the south-eastern Baltic proper in 1992-1996 and its impact on cod spawning conditions and distribution. ICES Comm Meet 1996/C+J:8

Glowinska A (1963) Hydrologic conditions in the southern Baltic in the years 1951-1960. Pr Morsk Inst Ryb Gdyni 12/A:23-85 (in Polish)

Grauman GB (1973) Investigations of factors influencing fluctuations in abundance of Baltic cod. Rapp PV Reun Cons Int Explor Mer 164:73-76

Heath M, Gallego A (1997) From the biology of the individual to the dynamics of the population: bridging the gap in fish early life studies. J Fish Biol (Supp) A) 1997:1-29

HELCOM (1996) Third periodic assessment of the state of the marine environment of the Baltic Sea, 1989-1993, background document. Proc Baltic Sea Environ Symp 64B:1-252

Hinrichsen HH, Wieland K (1996) Reproduction volume of Baltic cod in the Bornholm Basin estimated from single point measurements. ICES Comm Meet 1996/C+J:7

Hinrichsen HH, Lehmann A, St John MA, Brügge B (1997) Modelling the cod larvae drift in the Bornholm Basin in summer 1994. Cont Shelf Res 17:1765-1784

ICES (International Council for the Exploration of the Sea) (1997) Report of the Baltic Fisheries Assessment Working Group. ICES Comm Meet Assess (1997)12:1

ICES (1998) Report of the Study Group on Management Strategies for Baltic Fish Stocks. ICES Comm Meet ACFM (1998) 11:1

Jarre-Teichmann A, Wieland K, Mackenzie BR, Hinrichsen $\mathrm{HH}$, Aro $\mathrm{E}$, Plikshs $M$ (in press) Stock-recruitment relationships for cod (Gadus morhua callarias L.) in the central Baltic Sea incorporating environmental variability. Arch Fish Mar Sci

Kjesbu OS, Kryvi H, Sundby S, Solemdal. S (1997) Buoyancy variations in eggs of Atlantic cod (Gadus morhua L.) in relation to chorion thickness and egg size: theory and observations. J Fish Biol 41:581-599

Kosior M, Netzel J (1989) Eastern Baltic cod stocks and environmental conditions. Rapp PV Reun Cons Int Explor Mer 190:159-162

Mackenzie BR, St John MA, Plikshs M, Hinrichsen $\mathrm{HH}$ Wieland K (1996) Oceanographic processes influencing seasonal and interannual variability in cod spawning habitat in the eastern Baltic Sea. ICES Comm Meet 1996 C+J 4

Matthäus W (1978) Phytoplankton spring bloom and maximum oxygen content in the Baltic proper. Kiel Meeresforsch $4: 147-152$

Matthäus W. Franck H (1992) Characteristics of major Baltic inflows - a statistical analysis. Cont Shelf Res 12: 1375-1400
Matthäus W, Lass HU (1995) The recent salt inflow into the Baltic sea. J Phys Oceanogr 25:280-286

Nissling A, Westin L (1991) Egg buoyancy of Baltic cod (Gadus morhua) and its implications for cod stock fluctuations in the Baltic. Mar Biol 111:33-35

Nissling A, Kryvi H, Vallin L (1994) Variation in egg buoyancy of Baltic cod Gadus morhua and its implications for egg survival in prevailing conditions in the Baltic Sea. Mar Ecol Prog Ser 110:67-74

Plikshs M (1996) Recent changes in cod spawning stock abundance and reproduction success in the Gotland area: is the cod recovery possible? ICES Comm Meet 1996/J:23

Plikshs M, Kalejs M, Grauman G (1993) The influence of environmental conditions and spawning stock size on the yearclass strength of the eastern Baltic cod. ICES 1993/J 22

Rahm L, Conley D, Sandén, P, Wulff F, Stålnacke P (1996) Time series analysis of nutrient inputs to the Baltic Sea and changing DSi:DIN ratios. Mar Ecol Prog Ser 130: $221-228$

SAS Institute Inc (1985) SAS user's guide: statistics. Version 5 edn. Sas Institute Inc, Cary, NC

Schinke H, Matthäus W (1998) On the causes of major Baltic inflows - an analysis of long time series. Cont Shelf Res 18:67-97

Schnack D, Köster F, Wieland K, Rosenthal H, St John MA, Mackenzie, BR, Tomkiewicz J, Nissling A, Larsson PO, Aro E (1996) Baltic cod recruitment project (CORE) progress-report 1995/96. ICES Comm Meet 1996/J:181

Sparholt H (1996) Causal correleation between recruitment and spawning stock size of central Baltic cod? ICES J Mar Sci 53:771-779

Stigebrandt A (1987) A model for the vertical circulation of the Baltic dee water. Am Meteorol Soc 17:1772-1785

Stigebrandt A, Wulff F (1987) A model for the dynamics of nutrients and oxygen in the Baltic proper. J Mar Res 45:729-757

Viitasalo M, Vuorinen I, Saesmaa S (1995) Mesozooplankton dynamics in the northern Baltic Sea: implications of variations in hydrography and climate. J Plankton Res 17 $1857-1878$

Wasmund N, Nausch G, Matthäus W (1998) Phytoplankton spring blooms in the southern Baltic Sea - spatio-temporal development and long-term trends. J Plankton Res 20: 1099-111

Wieland K (1995) Einfluß der Hydrographie auf die Vertikalverteilung und Sterblichkeit der Eier des Ostseedorsches (Gadus morhua callarias) im Bornholmbecken, südliche zentrale Ostsee. Ber Inst Meereskunde Kiel 266:1-114

Wieland K, Horbowa K (1996) Recent changes in peak spawning time and location of spawning of cod in the Bornholm Basin, Baltic Sea. ICES Comm Meet 1996/J:15

Wieland K, Jarre-Teichmann A (1997) Prediction of vertical distribution and ambient development temperature of Baltic cod, Gadus morhua L., eggs. Fish Oceanogr 6 $172-187$

Wieland K, Waller U, Schnack D (1994) Development of Baltic cod eggs at different levels of temperature and oxygen content. Dana 10:163-177

Wlodarczyk E, Horbowa K (1997) Size-specific vertical distribution of Baltic cod (Gadus morhua L.) eggs in the Bornholm Basin in 1993 and 1994. ICES J Mar Sci 54:206-212

Zezera AS, Zezera ES (1997) Recent variations of hydrological regime in the south-eastern Baltic Sea and their impact upon cod spawning conditions. JCES Comm Meet 1997/U:13 